\title{
Article Withdrawn
}

This article has been withdrawn from publication on author's request 